\section{The Determination of Esterified (Unsplit) Fat in Faeces}

\section{S. L. TOMPSETT}

\author{
From the Biochemical Laboratory, Northern General \\ Hospital, Edinburgh
}

(RECEIVED FOR PUBLICATION MAY 4, 1956)

The method of choice for the determination of the total fat content of faeces appears to be that of Kamer, Huinink, and Weyers (1949) and Frazer (1956).

Although the value of the differential determination of esterified fatty acids (neutral fat, " unsplit" fat) is somewhat doubtful, it may be required on occasions. Certain difficulties have been encountered in the determination of this fraction by the method of Kamer et al. (1949) which is based on difference. For example, frequently values for split fat were found to exceed those for total fat. Such difficulties are frequently encountered when a component is measured by a difference procedure. Satisfactory results may, however, be obtained by a direct determination of esterified fatty acids. The material is treated with hydroxylamine in an alkaline medium and the resulting hydroxamic acids, formed from esters and not from free acids, are determined colorimetrically by the violet colour produced by ferric chloride in an acid medium. Many related methods have been described and in particular that of Stern and Shapiro (1953) for the determination of esterified fatty acids in plasma. The "unsplit" fat of faeces will consist of a mixture of mono, di, and triglycerides, and it has been found, in agreement with Stern and Shapiro, that the colour produced in the reaction is (1) proportional to the number of esterified carboxyl groups in the molecule, and (2) is independent of the length of the fatty acid molecule when glycerol is the alcohol present.

The method has advantages over the usual gravimetric difference procedures, since only esters are measured and not in addition non-saponifiable material, such as sterols, pigments, etc.

For convenience, standards are prepared from triolein (olive oil) and results are expressed in terms of esterified stearic acid in order that such are comparable with the determinations of total fat.

The complete procedure is as follows :

\section{Reagents}

(1) Concentrated hydrochloric acid, $10 \mathrm{ml}$, and $250 \mathrm{~g}$. sodium chloride are made up to 1 litre with water.
(2) Ethanol.

(3) Petroleum ether, B.P.

(4) Ethanol/ether mixture-3/1 (v/v).

(5) Hydroxylamine hydrochloride solution in water오․ $3.5 \%(0.5 \mathrm{M})$, is prepared freshly before use.

(6) Dilute hydrochloric acid solution, for which 1 volume of hydrochloric acid (sp. gr. 1.18) is diluted with 2 volumes of water.

(7) $0.37 \mathrm{M}$ ferric chloride in $0.1 \mathrm{~N}$ hydrochlori $\vec{\odot}$ acid.

(8) $3.5 \mathrm{~N}$ (aqueous) sodium hydroxide solution.

(9) Stock standard solution of triolein, for whic 5 to $6 \mathrm{~g}$. of olive oil is dissolved in $500 \mathrm{ml}$. of abso? lute ethanol. The exact strength is then determineक as follows: Of the ethanolic solution, $50 \mathrm{ml}$. $+50 \mathrm{mh}$ of $0.1 \mathrm{~N}$ (ethanolic) sodium hydroxide solution arês boiled under a reflux condenser for $\mathbf{4 0}$ minutes. Afteo cooling, the mixture is titrated with $0.1 \mathrm{~N}$ hydrog chloric acid against bromthymol blue as indicator Then triolein content $(\mathrm{mg}$.) $=29.7 \times(50-\mathrm{ml}$. 0.1 $\mathrm{HCl}$ used). The solution is then diluted with ethan 9 to a concentration of $10.36 \mathrm{mg}$. triolein $/ \mathrm{ml}$. One millilitre of this solution is equivalent to $10 \mathrm{mg}$. esterifieg stearic acid/ml.

(10) Dilute standard solution of triolein : for use th民 stock standard solution is diluted with ethanol/ethe mixture $(3 / 1)$ so that $6 \mathrm{ml}$. contains the equivalent of 1 mg. esterified stearic acid.

\section{Method}

A. Into a $100-\mathrm{ml}$. glass-stoppered measuring cylin der are measured $10 \mathrm{ml}$. of the faecal suspension and $22 \mathrm{ml}$. reagent 1 and mixed, then $40 \mathrm{ml}$. ethanol, and mixed again, and finally $50 \mathrm{ml}$. petroleum ether.

The mixture is shaken for two minutes and the allowed to settle, when $1 \mathrm{ml}$. of the petroleum ethe extract is evaporated to dryness.

B. The residue is dissolved in $6 \mathrm{ml}$. of ethanoB ether mixture (3/1) and the following added in order $1 \mathrm{ml}$. of hydroxylamine reagent and $1 \mathrm{ml}$. of $3.5 \mathrm{X}$ sodium hydroxide solution. The mixture is allowed to stand for 20 minutes at room temperature. The are added $1.2 \mathrm{ml}$. of dilute hydrochloric acid solution (reagent 6) and $1 \mathrm{ml}$. of $0.37 \mathrm{M}$ ferric chloride $0.1 \mathrm{~N} \mathrm{HCl}$. The colour is read at $525 \mathrm{~m} \mu$ against a blank prepared at the same time.

\section{Standard}

It is advisable to prepare a standard at the sante time containing the equivalent of $1 \mathrm{mg}$. esterified stearic acid in $6 \mathrm{ml}$. of ethanol/ether mixture.

\section{REFERENCES}

Frazer, A. C. (1956). Broadsheet No. 9 (New Series). The As\$ ciation of Clinical Pathologists.

Kamer, J. H. van do, Huinink, H. ten Bokkel, and Weyers, H. E. (1949). J. biol. Chem., 177, 347.

Stern. I., and Shapiro, B. (1953). Journal of Clinical Pathology, $\mathcal{C}^{6}$ 158. 